\title{
Rhinoscleroma Masquerading as a Nasopharyngeal Malignancy
}

\author{
Sana Parveen ${ }^{1}$, Shraddha Jain ${ }^{2}$ \\ 1,2 Department of Otorhinolaryngology, Datta Meghe Institute of Medical Sciences, \\ Sawangi (M), Wardha, Maharashtra, India.
}

\section{INTRODUCTION}

Klebsiella rhinoscleromatis, the causative agent of rhinoscleroma, is a Gram-negative, facultative intracellular, non-motile, encapsulated bacillus. The organism has a very low infectivity necessitating a chronic exposure for infection. Prevalence is also high in developing countries like India. The factors responsible for this are attributed to poor hygiene, poor access to medications and overcrowded living conditions. ${ }^{1}$ Though entire respiratory mucosa can be affected, the organism has an affinity for nasal mucosa and thus nasal cavity is the most prevalent site accounting for 95-100 $\%$ of cases. In decreasing order of involvement nasopharynx (18 - $43 \%)$, larynx (15 - $40 \%)$, trachea (12\%) and bronchi $(2-7 \%)$ are the other sites. ${ }^{2}$

Our patient had bilateral nasal obstruction and discharge since 6 months as the only presenting complaint. Clinically there was no evidence of lymphadenopathy, but the CT scans of the paranasal sinuses showed heterogeneously ill-defined mass in the posterior nasal cavity, raising suspicion of a malignancy. Hence the case was further investigated.

\section{PRESENTATION OF CASE}

A 54-year-old male farmer, presented to the ENT OPD in March 2020 with chief complaints of progressive nasal obstruction and nasal discharge for the past 6 months. The discharge was watery in consistency, intermittent in nature, more in the mornings. Patient complained of difficulty in breathing since past 2 - 3 months, with no predisposing history of tuberculosis or asthma, raising initial suspicion of the Coronavirus infection. He also complained of bilateral ear blockage and reduced hearing ever since these symptoms started.

General examination findings were unremarkable. There was no evidence of any visible or palpable cervical lymphadenopathy. He denied of any weight loss or night sweats. Local examination was also insignificant except for mild nasal mucosal congestion and bilateral inferior turbinate hypertrophy. No mass was seen on anterior rhinoscopy examination. Routine haematological and biochemical investigation findings were within the normal range.
Corresponding Author: Dr. Sana Parveen,

Room T-13, Shalinta P. G. Girls Hostel,

Datta Meghe Institute of Medical

Sciences, Sawanghi, Meghe,

Wardha, Maharashtra, India.

E-mail: Sanaparveen23@yahoo.com

DOI: $10.14260 /$ jemds/2021/518

How to Cite This Article:

Parveen S, Jain S. Rhinoscleroma masquerading as a nasopharyngeal malignancy. J Evolution Med Dent Sci 2021;10(31):2528-2531, $10.14260 /$ jemds/2021/518

Submission 16-01-2021,

Peer Review 30-05-2021

Acceptance 08-06-2021,

Published 02-08-2021.

Copyright (C) 2021 Sana Parveen et al. This is an open access article distributed under Creative Commons Attribution License [Attribution 4.0 International (CC BY 4.0)] 
Patient had got checked at a local hospital where a computed tomography of the paranasal sinuses (Figure 1) was done and the report was suggestive of an ill-defined mildly enhancing lesion in the nasopharynx and right parapharynx, completely blocking the right choanae and left choanae. The lesion was showing loss of fat plane with the prevertebral muscles but not with pterygoid muscles, and extending from oropharynx to the nasopharynx, but no bony erosion was seen. Few subcentimetric cervical lymph nodes were also seen enlarged on both sides on CT. The final diagnosis was neoplastic lesion of the nasopharynx.
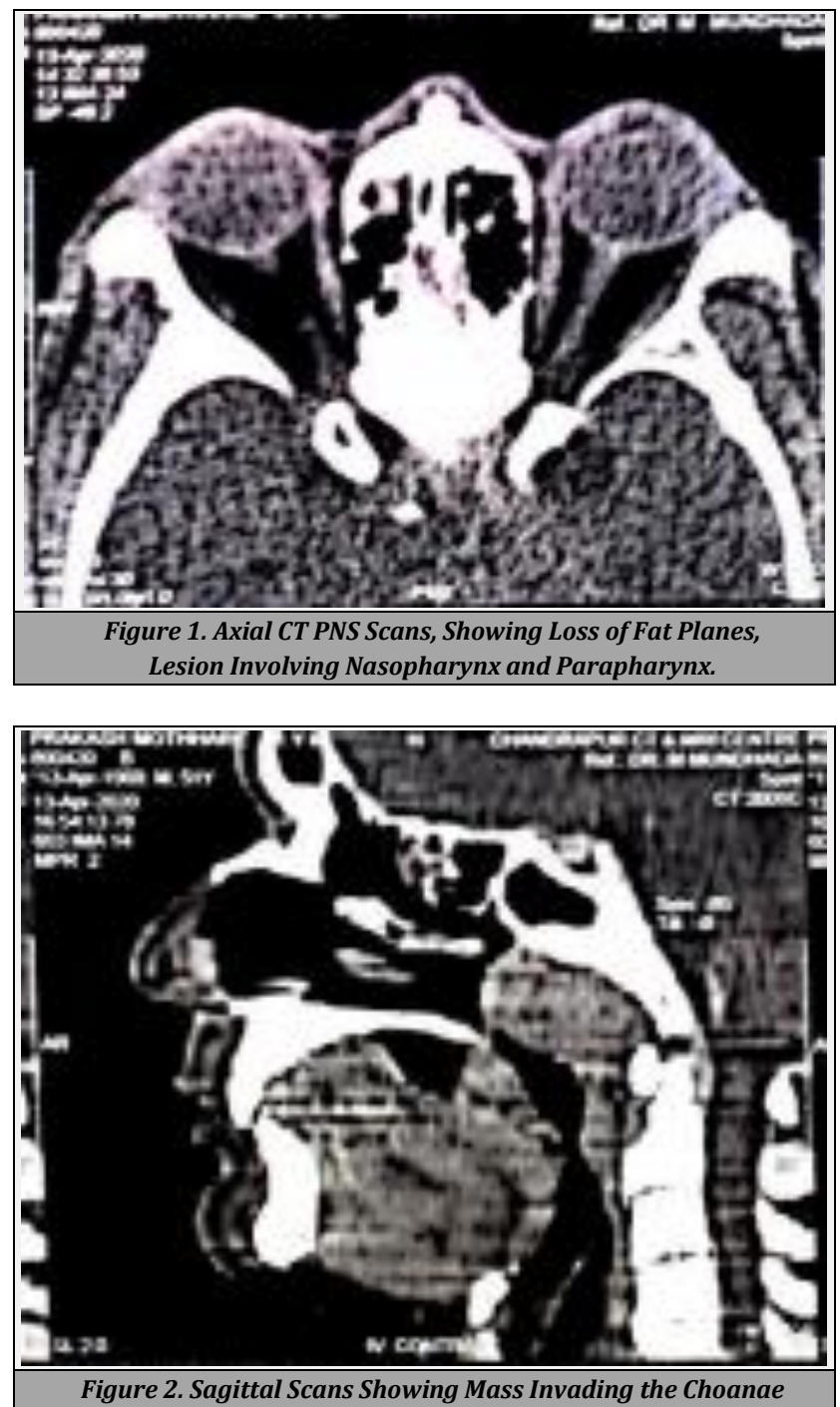

After testing negative for Covid-19, a biopsy under general anaesthesia was planned to confirm the diagnosis and on endoscopy the nasal cavity space was markedly reduced and the septum was thickened.

A highly vascularised mass was seen involving the nasopharynx, posterior nasal cavities and bilateral choanae, raising suspicion of a nasopharyngeal malignancy. (Figure 3 \& 4) Multiple biopsies were taken from the mass lesion.

Histopathological evaluation revealed squamous epithelial lining with a subepithelial tissue showing a dense, mixed inflammatory cell infiltrate containing plenty of plasma cells with many showing Russell bodies - eosinophilic structures within the cytoplasm of plasma cells and Mikulicz cells (large histiocytes with numerous vacuoles containing viable or nonviable bacteria) (Figure 3).

The Mikulicz cells were PAS positive. The organisms were characterized as Klebsiella granulomatis based on morphology.3 A final diagnosis of rhinoscleroma of the nasopharynx was made.

On the basis of histopathological reports, the patient was started on Tab doxycycline $500 \mathrm{mg}$ BD and Tab ciprofloxacin $500 \mathrm{mg}$ BD for 3 months. Repeat complete blood count was advised every 1 month in order to monitor the white blood cell count. Patient has been responding very well to the treatment and his symptoms are resolved completely at present. ${ }^{4} \mathrm{He}$ has been kept under regular observation to monitor any incidence of recurrence.
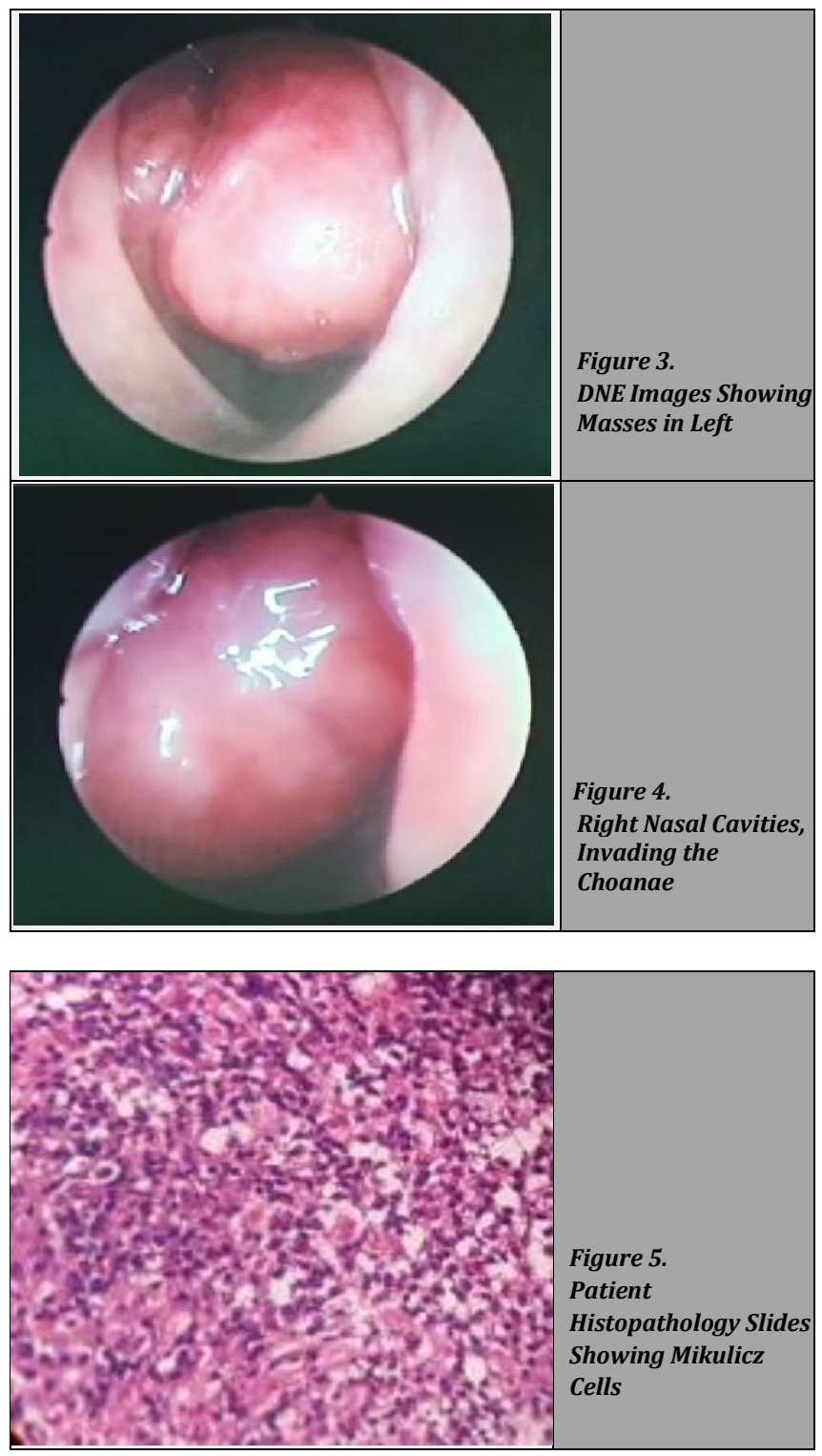

\section{DIFFERENTIAL DIAGNOSIS}

As the mass was seen arising in the nasopharynx on nasal endoscopy and obliterating the pterygoid muscles along with the fat planes, it gave the suspicion of nasopharyngeal malignancy. Hence histopathological diagnosis was necessary for confirmation. Some other chronic granulomatous diseases 
are to be kept in mind as differential diagnosis such as tuberculosis, actinomycosis and leprosy which can also produce granulomas in the upper airways.

Fungal infections including histoplasmosis, blastomycosis and sporotrichosis should also be considered. Other differential diagnosis consists of mucocutaneous leishmaniasis, malignancies ${ }^{5}$ such as basal cell carcinomas, lymphomas, which might present as an incidental finding on $\mathrm{CT}$, as well as inflammatory lesions such as sarcoidosis and Wegener's granulomatosis.

\section{PATHOLOGICAL DISCUSSION}

Rhinoscleroma as a pathological entity, was first described by Von Hebra in the year 1870. It's a granulomatous disease of the upper airway tract caused by Klebsiella granulomatis, which is an encapsulated, immotile and short Gram-negative bacillus. It has an affinity for nasal mucosa. Transmission of the infection is by either indirect or direct contact with aerosols of infected person. The most common site affected is the nasal cavity $(95$ - $100 \%)$ and then nasopharynx (18 - $43 \%)$, followed by the larynx (15 - $40 \%)$, trachea (12\%), and bronchi $(2-7 \%){ }^{6}$

Rhinoscleroma usually affects the nasal cavity but lesions in larynx, nasopharynx, oral cavity - soft and hard palate, paranasal sinuses, soft tissues of lips, nose, trachea and bronchi are also seen. $95 \%$ of scleromas are located in the nasal fossae involving the mucosa. In various studies done over the past 20 - 30 years, maximum cases of rhinoscleroma have been reported from the anterior nasal cavity, with anterior extensions; for example, to the septum, skin of external nose, and paranasal sinuses. Posterior extent or beginning of the infection of the posterior choanae has rarely been seen or reported, as in the case of our patient. ${ }^{7}$

Till now, nasopharyngeal involvement of rhinoscleroma has been reported from Germany, Rwanda, and Papua New Guinea but not from the South-East Asia and this is the first one, according to our knowledge. ${ }^{8}$ (Table 1 )

\begin{tabular}{|cccc|}
\hline Study & Location & Age / Sex & Site \\
$\begin{array}{c}\text { Molumi and } \\
\text { Dubey (2016) }\end{array}$ & Papua New Guinea & $\begin{array}{c}30-35 \text { yrs. } \\
27-\text { females } \\
32-\text { males }\end{array}$ & $\begin{array}{c}\text { Nasopharynx, most } \\
\text { common site }\end{array}$ \\
$\begin{array}{c}\text { Mukara et al. } \\
(2014)^{10}\end{array}$ & $\begin{array}{c}\text { Rwanda N }=7 \\
\text { Germany N }=1\end{array}$ & $\begin{array}{c}27-62 \text { yrs. } \\
4 \text { males }\end{array}$ & Nasopharynx, \\
$\begin{array}{c}\text { Bhowate et al. } \\
(2012)^{11}\end{array}$ & India & $14 /$ female & $\begin{array}{c}\text { Maxilla, orbital floor, } \\
\text { temporomandibular } \\
\text { joint }\end{array}$ \\
$\begin{array}{c}\text { Bigi et al. } \\
(2014)\end{array}$ & France & $46 /$ female & Trachea \\
$\begin{array}{c}\text { Ghosh et al. } \\
(1986)^{12}\end{array}$ & India & 47 male & Larynx and trachea \\
\hline $\begin{array}{r}\text { Table 1. Table Depicting Prevalence of Rhinoscleroma } \\
\text { According to Sites in the Body and Geographical Location }\end{array}$ \\
\hline
\end{tabular}

\section{DISCUSSION OF MANAGEMENT}

This chronic granulomatous infection is treated with longterm antibiotics and surgery in patients presenting with signs and symptoms of respiratory tract obstruction.

Antibiotics used include tetracycline, streptomycin, trimethoprim, sulfamethoxazole, rifampicin, and ciprofloxacin. In early stages of the disease, antibiotics alone might be sufficient. These are usually required for months to years to prevent recurrent infection.

In the presence of scarring or enlarged granulomas, surgery is often warranted. $\mathrm{CO} 2$ assisted endoscopic excision is mostly utilised in extensive, recurrent lesions.

\section{CONCLUSIONS}

Rhinoscleroma has a very deceptive clinical presentation, which may often lead to its misdiagnosis or underdiagnosing the disease. This case report depicts one such incidence of this infectious disease in Central India, one of the first of it's kind. In our patient, there was a nasopharyngeal mass present on CT PNS report, but no significant cervical lymphadenopathy or any other clinical suspicion of a malignancy was present except for the fact that a highly vascular lesion was seen on nasal endoscopy, which was extremely friable and bleeding on touching. Here, biopsy with accurate histopathology proved to be a great tool in resolving the enigma relating to the diagnosis of this condition. ${ }^{13}$

The objective of reporting this case was to shed light on the importance of occurrence of a granulomatous infectious disease with features of clinical suspicion of malignancy. Impaired humoral and cellular immunity in these infections can predispose patients to various other diseases. Delay in diagnosis can lead to residual nasal symptoms in spite of appropriate treatment. ${ }^{14}$

Financial or other competing interests: None.

Disclosure forms provided by the authors are available with the full text of this article at jemds.com.

\section{REFERENCES}

[1] Malkud S, Mahajan P. Rhinoscleroma: an unusual presentation. Indian Dermatol Online J 2018;9(3):191-3.

[2] Ghosh SN, Kesharwani A, Chaudhuri S, et al. Rhinoscleroma with intracranial extension: a rare case. Neurol India 2016;64(3):549-52.

[3] Nayak P, Pramod RC, Suresh KV, et al. Rhinoscleroma of nose extruding into oral cavity. J Coll Physicians Surg Pak 2015;25(Suppl 1):S27-9.

[4] Jage M, Rambhia KD, Khopkar US. Efficacy of doxycycline monotherapy in treating rhinoscleroma. Indian J Drugs Dermatol 2018;4(1):23-5.

[5] Santosh T, Kumar PM, Kumar BA, et al. Rhinoscleroma-a clinical mimicker of malignancy: a case report. J Cytol Histol 2005;6(6):1.

[6] Simons ME, Granato L, Oliveira RC, et al. Rhinoscleroma: case report. Braz J Otorhinolaryngol 2006;72(4):568-71.

[7] Badia L, Lund VJ. A case of rhinoscleroma treated with ciprofloxacin. J Laryngol Otol 2001;115(3):220-2.

[8] Umphress B, Raparia K. Rhinoscleroma. Arch Pathol Lab Med 2018;142(12):1533-6.

[9] Molumi CP, Dubey SP. Airway scleromas and their extensions. ANZ J Surg 2016;86(9):670-4.

[10] Mukara BK, Munyarugamba P, Dazert S, et al. Rhinoscleroma: a case series report and review of the 
literature. Eur Arch Otorhinolaryngol 2014;271(7):18516.

[11] Bhowate RR, Degwekar S, Rawlani S, et al. Rhinoscleroma wit hinvolvement of maxillary sinus, orbital floor and temporomandibular joint: a case report. J Oral Maxillofac Surg 2012;70(1):135-40.

[12] Ghosh NP, Sengupta NK. Rhinoscleroma of larynx and trachea. Indian J Otolaryngol 1986;38:145-8.
[13] Slager RE, Poole JA, Levan TD, et al. Rhinitis associated with pesticide exposure among commercial pesticide applicators in the agricultural health study. Occup Environ Med 2009;66(11):718-24.

[14] Ghazizadeh M, Yazdani N. Leprosy and rhinoscleroma: a rare case of concurrence. Arch Clin Infect Dis 2019;14(1):e63233. 